\title{
Assessment of Antimicrobial Activity of Various Concentrations of Commercially Available Tulsi (Ocimum Sanctum) Powder against Streptococcus Mutans
}

\author{
Gupta $B^{1, *}$, Kumar $V N^{2}$, Mallaiah $S^{2}$ \\ ${ }^{1}$ NIMS Dental College, Jaipur, Rajasthan, India \\ ${ }^{2}$ Dr. Syamala Reddy Dental College, Hospital and Research Centre, Bangalore, Karnataka, India \\ *Corresponding Author: dr.bhaskargupta@gmail.com
}

Copyright (C) 2013 Horizon Research Publishing All rights reserved.

\begin{abstract}
Aim: To assess the antimicrobial activity of various concentrations of Tulsi (Ocimum sanctum) extract, obtained from commercially available Tulsi powder, against Streptococcus mutans. Setting and design: Experimental design, in vitro study, Lab setting. Materials and methods: Ethanolic extract of Tulsi was prepared by the cold extraction method. The extract was then diluted with an inert solvent, dimethyl formamide, to obtain 7 different concentrations $(2 \%, 3 \%, 4 \%, 5 \%, 6 \%, 7 \%$ and $8 \%) .0 .2 \%$ chlorhexidine was used as a positive control and dimethyl formamide was used as a negative control. The extract, along with the controls, was then subjected to microbiological investigation to determine which concentration among the 7 different concentrations of the extract gave a wider inhibition zone against Streptococcus mutans. The zones of inhibition were measured in millimetres using a vernier caliper. Results: At the $6 \%$ concentration of Tulsi extract, a zone of inhibition of 27 millimetres $(\mathrm{mm})$ was obtained at a volume of $50 \mu \mathrm{l}$. This was the widest zone of inhibition observed among all the 7 different concentrations of Tulsi that were investigated. Conclusion: Tulsi extract demonstrated an antimicrobial property against Streptococcus mutans and can be used as a mouthwash. This could be further confirmed by in-vivo studies.
\end{abstract}

Key words Antimicrobial activity, Ocimum Sanctum, Streptococcus mutans, tulsi extract

\section{Introduction}

Dental caries is a disease of complex etiology. Microorganisms play an important role in the etiology of dental caries. There is substantial evidence that suggests that Streptococcus mutans is one of the main culprit microorganisms responsible for dental caries[1].
Reducing their levels in the oral cavity would provide an additional rationale for the prevention of dental caries. The responsibility is on the dentist to come up with robust, innovative, effective, feasible and new strategies to manage the disease. One such strategy would be to verify the enormous wealth of medicinal plants. Finding healing powers in plants is an ancient idea. People on all continents have long applied poultices and imbibed infusions of hundreds of indigenous plants dating back to the pre-history eras. Currently, of the one-quarter to one half of all pharmaceuticals dispensed in the United States having plant origins, very few are intended for use as antimicrobials[2].

Tulsi, scientifically known as Ocimum sanctum, is a time-tested premier medicinal herb. It is a plant of Indian origin, worshipped by the Hindus and used in Ayurvedic medicine since ancient times. It is one of the holiest and most sacred herbs grown widely in India. It is a herb that is bestowed with enormous antimicrobial substances and is used to treat a variety of illnesses ranging from diabetes mellitus, arthritis, bronchitis, skin diseases, etc[3-5]. Recent studies have also demonstrated significant anticancer properties of Ocimum sanctum[6]. Hence, it is also termed as the queen of herbs or the mother medicine of nature.

Literature review reveals that the antimicrobial property of Tulsi has been tested against a variety of microorganisms like Candida albicans, Staphyloccus aureus, enteric pathogens, Klebisella, Escherichia coli and Proteus[7]. It has also demonstrated anti-gonorrhoeal efficacy against multiresistant strains of Neisseria gonorrhoea and clinical isolates of beta lactamase-producing methicillin-resistant Staphylococcus aureus [8,9].

Chlorhexidine is used as a gold standard against which other antimicrobial agents are compared. It has been studied extensively and is currently the most potent chemotherapeutic agent against Streptococcus mutans and dental caries[10-13].

Consequently, chlorhexidine is also often used as a 
positive control for assessing the anticariogenic potential of other agents[14].

Therefore, an attempt is made to compare the antimicrobial activity of commercially available Tulsi powder with $0.2 \%$ chlorhexidine against Streptococcus mutans.

\section{Methodology}

An in-vitro study was designed to study and compare the antimicrobial activity of various concentrations of Tulsi (Ocimum sanctum) extract, obtained from commercially available Tulsi powder, against Streptococcus mutans.

\section{Preparation of Tulsi extract}

Commercially available Tulsi powder (Balaji's Tulsi Herbal Powder) is taken for the study.

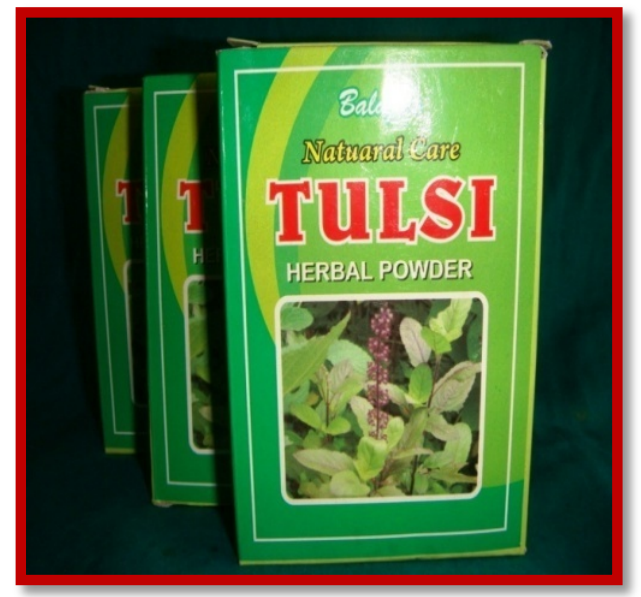

Figure 1. Commercially available Tulsi (Ocimum sanctum) powder

Three hundred grams of finely powdered Tulsi is then macerated with 500 millilitre (ml) of $100 \%$ ethanol.

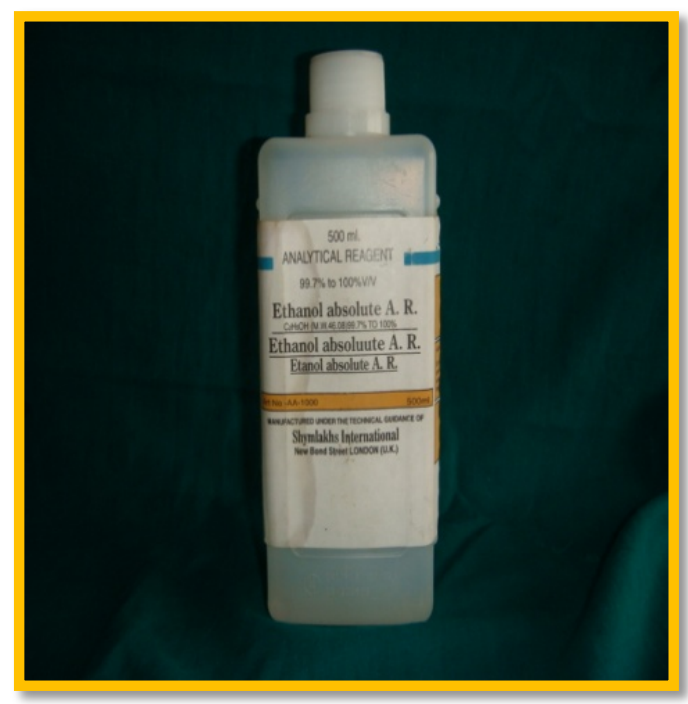

Figure 2. Ethanol
It is then subjected to filtration with Whatman filter paper to obtain a clear filtrate. The filtrate so obtained is reduced at a low temperature of less than $60^{\circ} \mathrm{C}$ to obtain a solid residue of Tulsi extract. From 300 grams of Tulsi powder dissolved in 1 litre (L) of ethanol, 18 grams of residue (extract) is obtained and thus the yield was $6 \% \mathrm{w} / \mathrm{w}$ (weight/weight)[15].



Figure 3. Pure Tulsi (Ocimum sanctum) extract

\section{Preparation of seven different concentrations of Tulsi extract}

One gram of extract is dissolved in $10 \mathrm{ml}$ of dimethyl formamide to obtain a $10 \%$ concentration of extract. One millilitre of the extract is transferred to a sterilized test tube and labeled as $10 \%$. The remaining $9 \mathrm{ml}$ of the extract is then diluted further with dimethyl formamide to obtain seven different concentrations ( $2 \%, 3 \%, 4 \%, 5 \%, 6 \%, 7 \%$ and $8 \%$ ).

$0.2 \%$ chlorhexidine is used as a positive control as it is the most potent chemotherapeutic agent against Streptococcus mutans. Dimethyl formamide is used as a negative control as it is an inert solvent and Streptococcus mutans is resistant to it, and is used to dilute Tulsi extract and to neutralize the effect of alcohol.

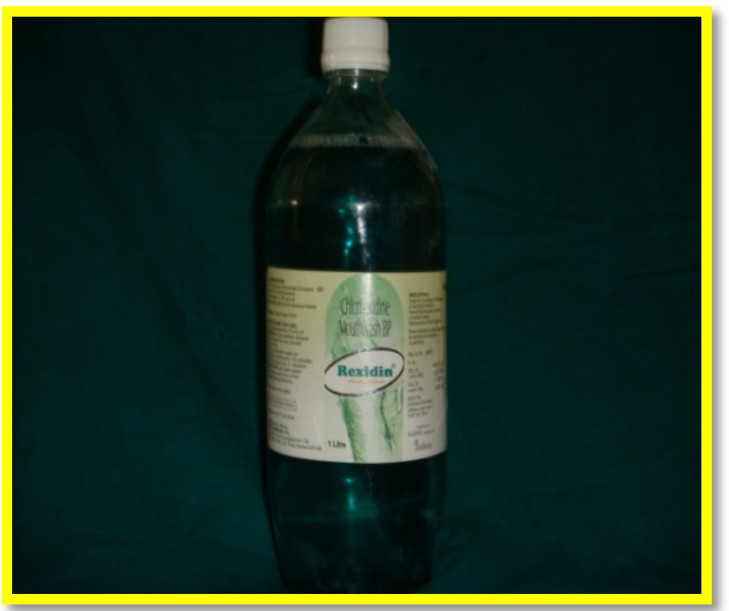

Figure 4. Chlorhexidine (positive control) 


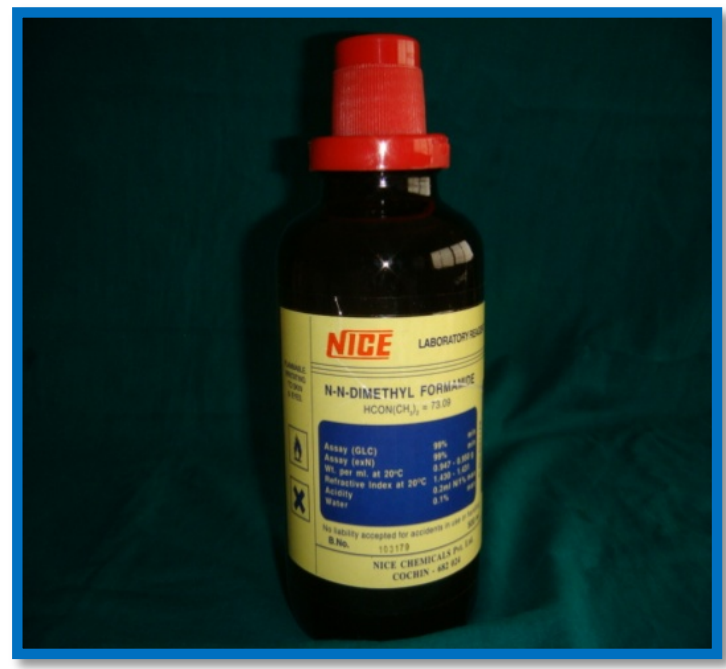

Figure 5. Dimethyl formamide (negative control)

\section{Microbiological procedures}

Pure strains of Streptococcus mutans (MTCC 890) are obtained from Microbial Type Culture Collection and Gene Bank (MTCC), Chandigarh.

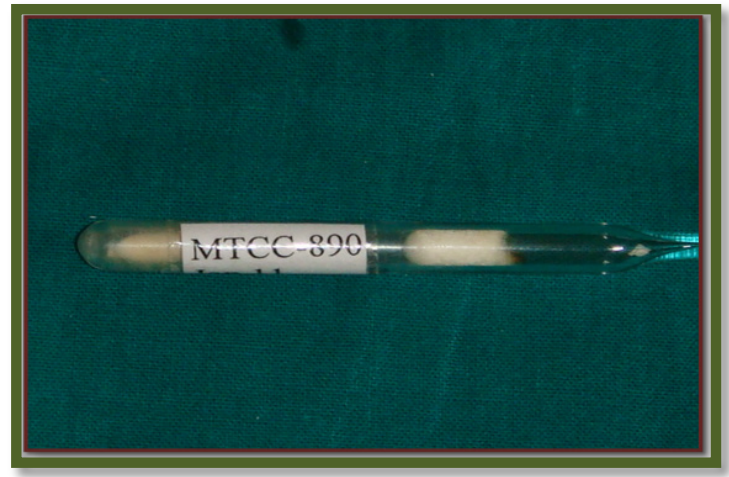

Figure 6. Pure strains of Streptococcus mutans

\section{Medium used}

Brain heart infusion agar is used as a medium.

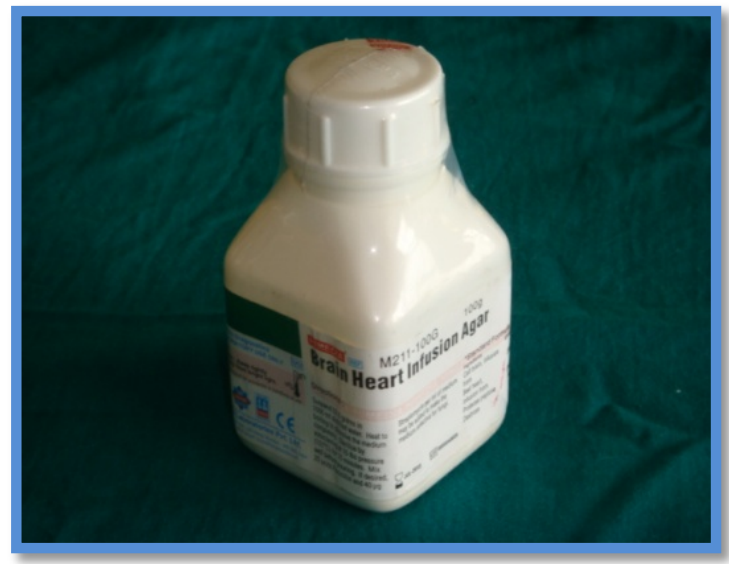

Figure 7. Brain heart infusion agar
The cup and plate method is used to determine the zone of inhibition. In this method, three circular wells that could incorporate three different volumes $(20 \mu \mathrm{l}, 30 \mu \mathrm{l}$ and $50 \mu \mathrm{l})$ of the test agent (Tulsi extract) are cut in the agar plates using a template.

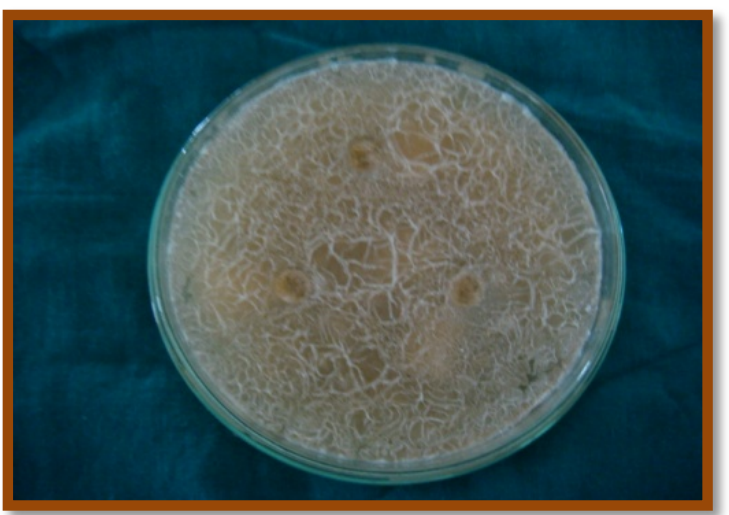

Figure 8. Prepared media with circular wells

Nine such plates were prepared and labeled, 07 for the 07 different concentrations of Tulsi extract (one plate each for one particular concentration) and one plate for positive control (chlorhexidine) and one plate for negative control (Dimethyl formamide), respectively.



Figure 9. Seven different con centrations $(2 \%, 3 \%, 4 \%$,

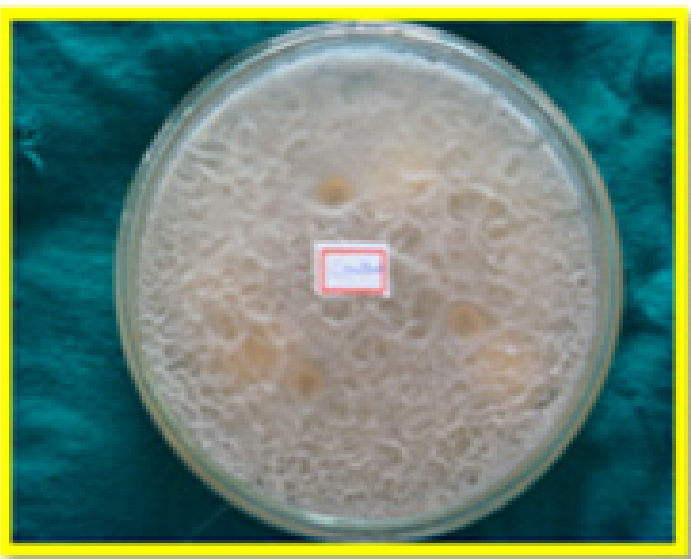

Figure10. Postive control 


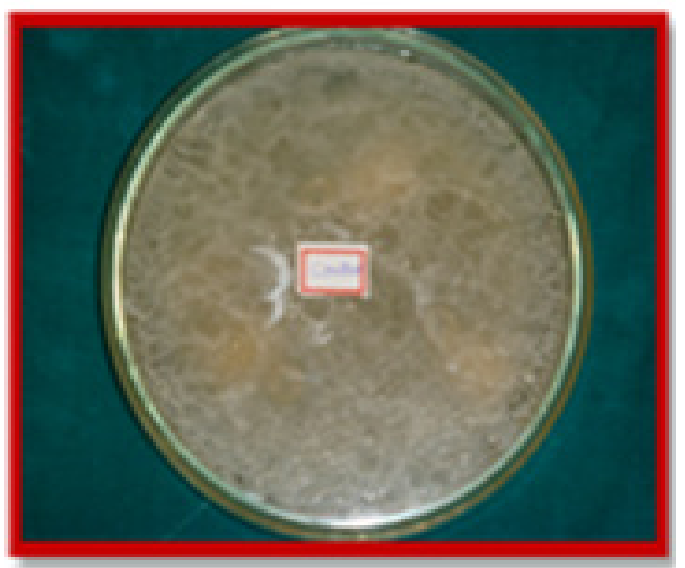

Figure 11. Negative control $5 \%, 6 \%, 7 \%$ and $8 \%$ ) of Tulsi powder

The different concentrations of extract, along with the controls, are transferred to the respective agar plates and these incubated aerobically at $37^{\circ} \mathrm{C}$ for 48 hours. The inhibition zones are measured using a vernier caliper[15].

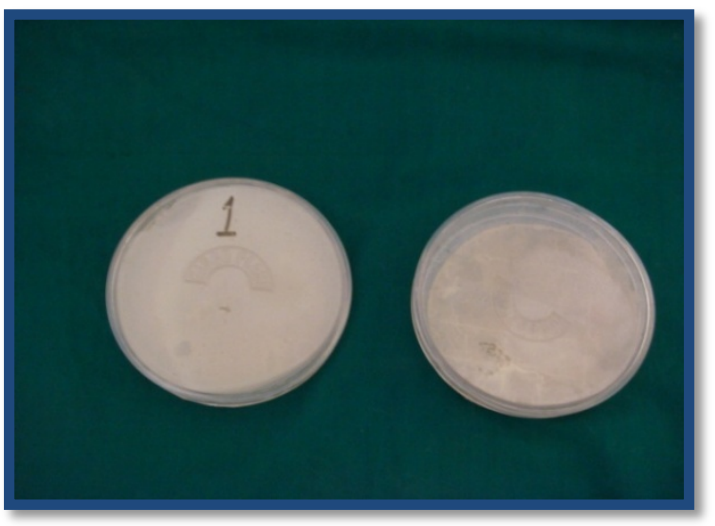

Figure 12. Growth of Strep mutans on brain heart infusion agar

\section{$\underline{\text { Statistical procedures }}$}

No statistical tests were performed as they were not required and the data obtained were appraised observationally.

\section{Results}

Table 1 shows zones of inhibition of different concentrations and volumes of Tulsi extract.

At $2 \%$ concentration, maximum zone of inhibition of 13 $\mathrm{mm}$ was achieved at a volume of $50 \mu \mathrm{l}$. At lower volumes of $20 \mu \mathrm{l}$ and $30 \mu \mathrm{l}$ of $2 \%$ concentration, there were no zones of inhibition.

At $3 \%$ concentration, a maximum zone of inhibition of 15 $\mathrm{mm}$ was achieved at a volume of $50 \mu \mathrm{l}$. At lower volumes of $20 \mu \mathrm{l}$ and $30 \mu \mathrm{l}$ of $3 \%$ concentration, there were no zones of inhibition.

A maximum zone of inhibition of $16 \mathrm{~mm}$ was achieved at $4 \%$ concentration with $50 \mu \mathrm{l}$ volume. At lower volumes of 20 $\mu \mathrm{l}$ and $30 \mu \mathrm{l}$ at $4 \%$ concentration, the zones of inhibition were $10 \mathrm{~mm}$ and $14 \mathrm{~mm}$ respectively.

At $5 \%$ concentration, a maximum zone of inhibition of 20 $\mathrm{mm}$ was achieved at a volume of $50 \mu \mathrm{l}$. At lower volumes of $20 \mu \mathrm{l}$ and $30 \mu \mathrm{l}$ at $5 \%$ concentration, the zones of inhibition were $16 \mathrm{~mm}$ and $18 \mathrm{~mm}$ respectively.

However, at $6 \%$ concentration, a maximum zone of inhibition of $27 \mathrm{~mm}$ was achieved at a volume of $50 \mu \mathrm{l}$. At lower volumes of $20 \mu \mathrm{l}$ and $30 \mu \mathrm{l}$ at $6 \%$ concentration, the zones of inhibition were $16 \mathrm{~mm}$ and $25 \mathrm{~mm}$ respectively.

At $7 \%$ concentration, a maximum zone of inhibition of 16 $\mathrm{mm}$ was achieved at a volume of $50 \mu \mathrm{l}$. At lower volumes of $20 \mu \mathrm{l}$ and $30 \mu \mathrm{l}$ at $7 \%$ concentration, the zones of inhibition were $10 \mathrm{~mm}$ and $14 \mathrm{~mm}$ respectively.

At $8 \%$ concentration, a maximum zone of inhibition of 18 mm was achieved with $50 \mu \mathrm{l}$ volume. At lower volumes of $20 \mu \mathrm{l}$ and $30 \mu \mathrm{l}$ at $8 \%$ concentration, the zones of inhibition were $11 \mathrm{~mm}$ and $16 \mathrm{~mm}$ respectively.

Table 1. Zones of inhibition of different concentrations and volumes of tulsi extract

\begin{tabular}{|c|c|c|c|}
\hline Volumes & $20 \mu \mathrm{l}$ & $30 \mu \mathrm{l}$ & $50 \mu \mathrm{l}$ \\
\hline Concentrations & \multicolumn{3}{|c|}{ Zones of inhibition } \\
\hline $2 \%$ & Resistant & Resistant & $13 \mathrm{~mm}$ \\
\hline $3 \%$ & Resistant & Resistant & $15 \mathrm{~mm}$ \\
\hline $4 \%$ & $10 \mathrm{~mm}$ & $14 \mathrm{~mm}$ & $16 \mathrm{~mm}$ \\
\hline $5 \%$ & $16 \mathrm{~mm}$ & $18 \mathrm{~mm}$ & $20 \mathrm{~mm}$ \\
\hline $6 \%$ & $16 \mathrm{~mm}$ & $25 \mathrm{~mm}$ & $27 \mathrm{~mm}$ \\
\hline $7 \%$ & $10 \mathrm{~mm}$ & $14 \mathrm{~mm}$ & $16 \mathrm{~mm}$ \\
\hline $8 \%$ & $11 \mathrm{~mm}$ & $16 \mathrm{~mm}$ & $18 \mathrm{~mm}$ \\
\hline
\end{tabular}

Table 2 shows zones of inhibition of different volumes at a concentration of $0.2 \%$ chlorhexidine (positive control). At $0.2 \%$ concentration, a maximum zone of $28 \mathrm{~mm}, 34 \mathrm{~mm}$ and $37 \mathrm{~mm}$ was formed at $20 \mu \mathrm{l}, 30 \mu \mathrm{l}$ and $50 \mu \mathrm{l}$ respectively.

Table 2. Zones of inhibition of different volumes at a concentration of $0.2 \%$ chlorhexidine (positive control)

\begin{tabular}{|c|c|c|c|}
\hline Volumes & $20 \mu \mathrm{l}$ & $30 \mu \mathrm{l}$ & $50 \mu \mathrm{l}$ \\
\hline Concentrations & \multicolumn{3}{|c|}{ Zones of inhibition } \\
\hline $0.2 \%$ chlorhexidine & $28 \mathrm{~mm}$ & $34 \mathrm{~mm}$ & $37 \mathrm{~mm}$ \\
\hline
\end{tabular}

Table 3 shows zones of inhibition of different volumes of dimethyl formamide (negative control). Streptococcus mutans was resistant to dimethyl formamide at volumes of $20 \mu \mathrm{l}, 30 \mu \mathrm{l}$ and $50 \mu \mathrm{l}$.

Table 3. Zones of inhibition of different volumes of dimethyl formamide (negative control)

\begin{tabular}{|c|c|c|c|}
\hline \multirow{2}{*}{ Volumes } & \multicolumn{3}{|c|}{ Dimethyl formamide } \\
\cline { 2 - 4 } & $20 \mu \mathrm{l}$ & $30 \mu \mathrm{l}$ & $50 \mu \mathrm{l}$ \\
\hline $\begin{array}{c}\text { Zones of } \\
\text { inhibition }\end{array}$ & Resistant & Resistant & Resistant \\
\hline
\end{tabular}




\section{Discussion}

Ocimum sanctum Linn., the plants of genus Ocimum belonging to family Labiatae are very important for their therapeutic potentials[16,17]. It is a multi-branched, small, erect, soft, stout and aromatic herb about $75 \mathrm{~cm}$ high. This is commonly known as Vishnu-Priya, Tulsi in Sanskrit, Kala-Tulsi in Hindi and India's Holy Basil in English.

It is found and cultivated throughout India and worshiped in temples and houses of Hindus.

Commonly, two types of Ocimum sanctum Linn (Ocimum sanctum $L$ ) are cultivated, namely tulsi plants with green leaves known as Sri Tulsi \& tulsi plants with purple leaves known as Krishna Tulsi. The leaves, seeds and root of this plant have been used in indigenous Ayurvedic medicine for therapeutic purposes as an expectorant, analgesic, anticancer, anti-asthmatic, antiemetic, diaphoretic, anti-diabetic, anti-fertility, hepatoprotective, hypotensive, hypolipidmic, and anti-stress agents. Tulsi has also been used in treatment of fever, bronchitis, arthritis, convulsions etc[3, 18].

The chemical composition of Tulsi is highly complex, containing many nutrients and other biologically active compounds. The nutritional and pharmacological properties of the whole herb in its natural form result from synergistic interactions of many different active phytochemicals. Although Tulsi is known as a general vitalizer and increases physical endurance, it contains no caffeine or other stimulants[19]. The therapeutic potential of Tulsi has been found to be largely due to eugenol, a major constituent of the essential oil, which is a phenolic compound (1-hydroxy-2-methoxy-4- allylbenzene). The other important constituents include ursolic acid and carvacrol which also has antimicrobial activity[3].

In the present study, commercially available tulsi powder (Balaji's Tulsi Herbal Powder) was used to compare the antimicrobial activity with $0.2 \%$ chlorhexidine (positive control) against Streptococcus mutans. Ethanol, a type of alcohol, was used as a solvent because the essential oils in Tulsi were more soluble in alcohol as compared to distilled water. Dimethyl formamide was used as a negative control in this study. It was an inert solvent and used to dilute tulsi extract and to neutralize the effect of alcohol.

In the present study, 6\% concentration of Tulsi extract, obtained from commercially available Tulsi powder was found most effective and had maximum antimicrobial potential against Streptococcus mutans (Table 1). However, Agarwal et al[15] reported 4\% concentration of Tulsi extract, when Tulsi leaves were obtained from courtyard, had maximum antimicrobial potential against Streptococcus mutans. The difference demonstrated in the antimicrobial activity potential against Streptococcus mutans might be due to using of commercial Tulsi powder in this study for preparing Tulsi extract, which might not be equally pure as Tulsi extract prepared from Tulsi leaves directly obtained from courtyard.

In the present study, chlorhexidine (positive control) was found to be more effective when compared to Tulsi extract, obtained from commercially available Tulsi powder (Table 2). However, the well-known side-effect of Chlorhexidine, i.e. staining of teeth and restoration, alteration of taste sensation and development of resistant microorganisms, may limit the long-term use of chlorhexidine[20]. In comparison with herbal medicines, Tulsi is abundantly available, easily accessible, economically feasible and culturally acceptable and may possess minimal side-effects, hence it can be recommended for long-term use[21].

In the present study, Streptococcus mutans was resistant to dimethyl formamide (Table 3). Agarwal et al[15] also reported Streptococcus mutans resistance against dimethyl formamide. This was due to fact that it was an inert solvent and used to dilute the tulsi extract and to neutralize the effect of alcohol, attributing the result solely to tulsi.

\section{Conclusion}

The present study demonstrated the maximum antimicrobial activity against Streptococcus mutans, using tulsi extract, obtained from commercially available Tulsi powder, at $6 \%$ concentration level and can be used as a mouthwash. However, further studies are required to confirm the composition and side effects of tulsi extract, obtained from commercially available Tulsi powder on human beings.

\section{REFERENCES}

[1] Balakrishnan M, Simmonds RS, Tagg JR. Dental caries is a preventable infectious disease. Aust Dent J 2000;45:235-45.

[2] Cowan MM. Plant product as antimicrobial agents. Clin Microbiol Rev 1999;24:564-82.

[3] Prakash P, Gupta N. Therapeutic uses of Ocimum sanctum linn (Tulsi) with a note on eugenol and its pharmacological actions: A short review. Indian J Physiol Pharmacol 2005;49:125-31.

[4] Bhat M, Zinjarde SS, Bhargava SY, Kumar AR, Joshi BN. Antidiabetic Indian plants: A good source of potent amylase inhibitors. Evid Based Complement Alternat Med 2008 [In Press].

[5] Viyoch J, Pisutthanan N, Faikreua A, Nupangta K, Wangtorpol K, Ngokkuen J. Evaluation of in vitro antimicrobial activity of Thai basil oils and their micro-emulsion formulas against Propionibacterium acnes. Int J Cosmet Sci 2006;28:125-33.

[6] Magesh V, Lee JC, Ahn KS, Lee HJ, Lee EO, Shim BS, et al. Ocimum sanctum induces apoptosis in A549 lung cancer cells and suppresses the in vivo growth of Lewis lung carcinoma cells. Phytother Res 2009;23:1385-91.

[7] Geeta, Vasudevan DM, Kedlaya R, Deepa S, Ballal M. Activity of Ocimum sanctum (the traditional Indian medicinal plant) against enteric pathogens. Indian $\mathrm{J}$ Med Sci 2001;55:434-8, 472. 
[8] Shokeen P, Bala M, Sing M, Tandon V. In vitro activity of eugenol, an active component from Ocimum sanctum, against multiresistant and susceptible strains of Neisseria gonorrhea. Int J Antimicrob Agents 2008;32:172-9.

[9] Aqil F, Khan MS, Owais M, Ahmad I. Effect of certain bioactive plant extracts on clinical isolates of beta-lactamase producing methicillin resistant Staphylococcus aureus. J Basic Microbiol 2005;45:106-14.

[10] Emilson CG. Outlook for hibitane in dental caries. J Clin Periodontol 1977a;4:136-43.

[11] Loesche WJ. Antimicrobials can they be effective? In: Guggenheim B, editor. Cariology today. Zurich: Karger; 1984. p. 293-300.

[12] Meurmann JH. Chemotherapy of Streptococcus mutans. Proc Finn Dent Soc 1986;82:305-11.

[13] Kidd EA. Role of chlorhexidine in the management of dental caries. Int Dent J 1991;41:279-86.

[14] Emilson CG. Potential efficacy of chlorhexidine against mutans streptococci and human dental caries. J Dent Res 1994;73:682-91.

[15] Agarwal P., Nagesh L, Murlikrishnan. Evaluation of antimicrobial activity of various concentrations of Tulsi (Ocimum sanctum) extract against Streptococcus mutans: an in vitro study. Indian J Dent Res 2010;21:357-9.

[16] Gupta SK, Prakash J, Srivastava S. Validation of claim of Tulsi, Ocimum sactum Linn as a medicinal plant. Indian J Experimental Biology 2002;40(7):765-73.

[17] Nagarajun S, Jain HC, Aulakh GS. Indegeous plants used in fertility control. In: Atal $\mathrm{CK}$ and Kapoor BM (Eds). Cultivation and utilization of medicinal plants. (Published by PID CSIR) 1989:558.

[18] Mohan L, Mohan Babu V.A, Kumari M. Ocimum sanctum linn (tulsi) - an overview. Indian J of Pharmacol Sci, Rev and Res. Apr 2011;7(1):51-53.

[19] Miller R, Miller S. Tulsi queen of herbs, India's holy basil. Available from: http://www.nywellnessguide.com/nutiention/070410-TulsiH erbs.php (downloaded on May 19, 2011)

[20] Fardal O, Turnball RS. A review of literature on use of chlorhexidine in dentistry. J Am Dent Assoc 1986 Jun;112(6):863-9.

[21] Malhotra R, Grover V, Kapoor A, Saxena D. Comparison of the effectiveness of a commercially available herbal mouthrinse with chlorhexidine gluconate at the clinical and patient level. J Indian Soc Periodontol. 2011 Oct;15(4):349-52. 